\title{
Ten-year clinical experience of humanitarian cardiothoracic surgery in Rwanda: Building a platform for ultimate sustainability in a resource-limited setting
}

\author{
JaBaris D. Swain, MD, MPH, ${ }^{\mathrm{a}, \mathrm{b}}$ Colleen Sinnott, BS, ${ }^{\mathrm{b}}$ Suellen Breakey, RN, PhD, \\ Rian Hasson Charles, MD, ${ }^{\mathrm{d}}$ Gita Mody, MD, MPH, ${ }^{\mathrm{e}}$ Napthal Nyirimanzi, MD, ${ }^{\mathrm{f}}$ \\ Ceeya Patton-Bolman, RN, MSN,${ }^{\mathrm{g}}$ Patricia Come, MD, ${ }^{\mathrm{h}}$ Gapira Ganza, MD, ${ }^{\mathrm{i}}$ Emmanuel Rusingiza, MD, \\ Nathan Ruhamya, MD, ${ }^{\mathrm{k}}$ Joseph Mucumbitsi, MD, ${ }^{\mathrm{k}}$ Jorge Borges, MD, PhD, ${ }^{1}$ Martin Zammert, MD, ${ }^{\mathrm{m}}$ \\ Jochen D. Muehlschlegel, MD, MSc, ${ }^{\mathrm{m}}$ Robert Oakes, MD, ${ }^{\mathrm{n}}$ Bruce Leavitt, MD, ${ }^{\circ}$ and \\ R. Morton Bolman III, MD ${ }^{\circ}$
}

\section{ABSTRACT}

Objective: Despite its near complete eradication in resource-rich countries, rheumatic heart disease remains the most common acquired cardiovascular disease in sub-Saharan Africa. With a ratio of physicians/population of 1 per 10,500, including only 4 cardiologists for a population of 11.4 million, Rwanda represents a resource-limited setting lacking the local capacity to detect and treat early cases of strep throat and perform lifesaving operations for advanced rheumatic heart disease. Humanitarian surgical outreach in this region can improve the delivery of cardiovascular care by providing sustainability through mentorship, medical expertise, training, and knowledge transfer, and ultimately the creation of a cardiac center.

Methods: We describe the experience of consecutive annual visits to Rwanda since 2008 and report the outcomes of a collaborative approach to enable sustainable cardiac surgery in the region. The Ferrans and Powers Quality of Life Index tool's Cardiac Version (http://www.uic.edu/orgs/qli/) was administered to assess the postoperative quality of life.

Results: Ten visits have been completed, performing 149 open procedures, including 200 valve implantations, New York Heart Association class III or IV, with $4.7 \%$ 30-day mortality. All procedures were performed with the participation of local Rwandan personnel, expatriate physicians, nurses, residents, and support staff. Early complications included cerebrovascular accident $(n=4)$, hemorrhage requiring reoperation $(n=6)$, and death $(n=7)$. Quality of life was assessed to further understand challenges encountered after cardiac surgery in this resource-limited setting. Four major domains were considered: health and functioning, social and economic, psychologic/spiritual, and family. The mean total quality of life index was $20.79 \pm 4.07$ on a scale from 0 to 30 , for which higher scores indicated higher quality of life. Women had significantly lower "social

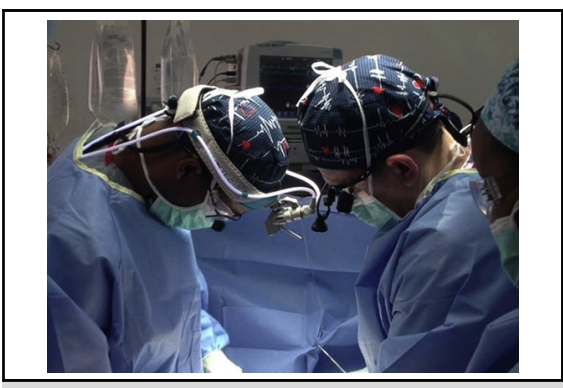

Ten-year clinical experience of cardiac surgery in Rwanda.

Central Message

This report represents the first account of a long-term humanitarian effort to develop sustainability in cardiac surgery in a resource-limited setting.

\section{Perspective}

This report represents the first account of a long-term humanitarian effort to develop sustainability in cardiothoracic surgery in Rwanda. Moving forward, preventive measures of acute rheumatic fever and RHD should be among health prevention program priorities. Team Heart has laid the foundation for a comprehensive program that could eventually eliminate RHD from the country.

See Editorial Commentaries pages 2551 and 2553.

\footnotetext{
From the 'Department of Surgery, Brigham and Women's Hospital, Boston, Mass; ${ }^{\mathrm{b}}$ Harvard Medical School, Boston, Mass; ${ }^{\mathrm{c}}$ Massachusetts General Hospital Institute of Health Professions, Boston, Mass; ${ }^{\mathrm{d}}$ Division of Cardiac Surgery, The Ohio State University, Columbus, Ohio; ${ }^{\mathrm{e}}$ Division of Thoracic Surgery, Brigham

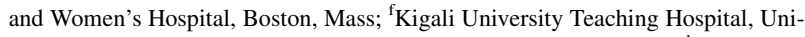
versity of Rwanda, Kigali, Rwanda; ${ }^{\mathrm{g}}$ Team Heart, Inc, Boston, Mass; ${ }^{\mathrm{h}}$ Division of Cardiology, Harvard Vanguard, Boston, Mass; ${ }^{\mathrm{i}}$ Kanombe Military Hospital of Rwanda, Kigali, Rwanda; ${ }^{\mathrm{j}}$ Kigali University Teaching Hospital, University of Rwanda, Kigali, Rwanda; ${ }^{k}$ King Faisal Hospital, Kigali, Rwanda; ${ }^{~ D i v i s i o n ~ o f ~ C a r-~}$ diology, Massachusetts General Hospital, Boston, Mass; ' Department of Anesthesiology, Perioperative, and Pain Medicine, Brigham and Women Hospital, Boston,

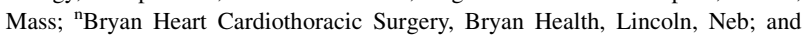
${ }^{\circ}$ University of Vermont Medical Center, Burlington, Vt.
}

In-kind support for Team Heart has been from St Jude Medical, Inc, Medtronic, Inc Edwards Lifesciences, Sorin, Inc, Ethicon, University of Vermont Medical Center, Brigham and Women's Hospital; Grants-in-aid from Edwards Lifesciences, St Jude Medical, Inc; Every Heartbeat Matters grant recipients from Thoracic Surgery Foundation for Research and Education, 2015, 2016, and 2017.

Read at the 97th Annual Meeting of The American Association for Thoracic Surgery, Boston, Massachusetts, April 29-May 3, 2017.

Received for publication June 1, 2017; revisions received Oct 28, 2017; accepted for publication Nov 14, 2017; available ahead of print Feb 27, 2018.

Address for reprints: JaBaris D. Swain, MD, MPH, Brigham and Women's Hospital, 75 Francis St, Boston, MA 02115 (E-mail: jswainmd@yahoo.com).

0022-5223/\$36.00

Copyright (C) 2018 by The American Association for Thoracic Surgery

https://doi.org/10.1016/j.jtcvs.2017.11.106 


\section{Abbreviations and Acronyms \\ $\mathrm{QOL}=$ quality of life \\ RHD $=$ rheumatic heart disease}

Scanning this $Q R$ code will take you to a supplemental video. To view the AATS Annual Meeting Webcast, see the URL next to the webcast thumbnail.

and economic" subscores $(16.81 \pm 4.17)$ than men $(18.64 \pm 4.10)(P<.05)$. Patients who reported receiving their follow-up care in rural health centers also had significantly lower "social and economic" subscores $(15.67 \pm 3.81)$ when compared with those receiving follow-up care in urban health facilities $(18.28 \pm 4.16)$ $(P<.005)$. Value afforded to family and psychologic factors remained high among all groups. Major postsurgical challenges faced included barriers to follow-up and systemic anticoagulation.

Conclusions: This report represents the first account of a long-term humanitarian effort to develop sustainability in cardiac surgery in a resource-limited setting, Rwanda. With the use of volunteer teams to deliver care, transfer knowledge, and mentor local personnel, the results demonstrate superior outcomes and favorable indices of quality of life. The credibility gained over a decade of effort has created the opportunity for a partnership with Rwanda to establish a dedicated center of cardiac care to assist in mitigating the burden of cardiovascular disease throughout sub-Saharan Africa. (J Thorac Cardiovasc Surg 2018;155:2541-50)

Disproportionately affecting low- and middle-income countries and chiefly regions of pervasive poverty, cardiovascular disease is responsible for more than one third of all deaths worldwide. ${ }^{1}$ In excess of three quarters of these deaths occur in low- and middle-income countries. The consequential burden is directly related to the paucity of integrated primary health care programs designed to facilitate early detection and treatment of individuals with risk factors in these regions. The result is a surge in late detection or delayed diagnosis that leads to premature death during early adulthood, the most economically productive years of life. ${ }^{1,2}$

Of the constellation of cardiovascular diseases that saturate these areas, rheumatic heart disease (RHD) is responsible for a worldwide toll of more than 1 million untimely deaths per year. ${ }^{2}$ As the most common acquired cardiovascular disease among children and adolescents in sub-Saharan Africa, RHD steadily confers severe disability in this region despite its near eradication in high-income countries. ${ }^{3}$ The prevalence of RHD in sub-Saharan Africa among children aged 5 to 14 years is 5.7 per 1000 , whereas in developed countries it is only 0.5 per $1000 .{ }^{4}$

Rwanda is a small, mountainous East African country with a population of approximately 12 million people. The capital city Kigali, located in the center of the country, contains the only hospital in Rwanda capable of hosting a visiting cardiac surgery team. This facility, King Faisal Hospital, was built with Saudi funding in the 1960s and was the site of killing of many doctors and nurses during the genocide. Now, with 1 physician per 10,500 individuals, including only 4 cardiologists in the public sector for a population of 11.4 million people, Rwanda represents a resource-limited setting that lacks the local capacity to detect, prevent, and treat early cases. As a result, RHD in this region often advances unchecked to critical stages, requiring surgical intervention. However, surgery has not been possible in vast majority of instances because of socioeconomic and health systems barriers. ${ }^{5-7}$ Also, the cost of medical management of end-stage RHD requires enormous investment, leading to personal or family debt. ${ }^{6,7}$ In this desperately resource-limited circumstance, the option of local partnership with humanitarian surgical outreach may represent a tenable solution to improving the delivery of cardiovascular care. This can occur through mentorship, medical expertise, training, knowledge transfers, and ultimately delivery of sustainable and safe cardiovascular surgery. However, access to this type of care has remained largely unavailable in resource-limited settings. With the exclusion of South Africa, the availability of cardiac surgery centers per million of inhabitants in sub-Saharan Africa is 1 program for every 33 million people. By comparison, in the United States, the ratio is 1 program for every 120,000 people, representing a striking global health disparity. ${ }^{8}$ These data explain why millions of young patients worldwide with rheumatic or congenital heart disease are declined treatment or are unable to receive lifesustaining operations each year. ${ }^{4}$

\section{QUALITY OF LIFE AFTER CARDIAC SURGERY IN RWANDA}

To date, there exist accounts of successful and failed attempts to provide sophisticated cardiovascular care, including cardiac surgery, to underdeveloped regions like Rwanda. ${ }^{9,10}$ However, no literature has yet investigated the postoperative quality of life (QOL) among patients with RHD in a resource-limited setting, a critical step in assessing the value of valve replacement or repair in such settings. QOL may be affected by such factors as the patient's gender, age, degree of social support, location of the primary health center for follow-up care, or type of valve 
replacement used. Mechanical valves last longer than bioprosthetic valves but require lifelong anticoagulation therapy, and bioprostheses are prone to early degeneration in young patients but do not require lifelong anticoagulation.

Ten years after implementing a program to provide cardiac surgery in Rwanda, we summarize surgical outcomes to date. We also quantify the QOL of patients who have undergone open surgery in Rwanda and identify the impact of lifelong anticoagulation therapy on patient self-reported QOL. We investigate the geographic determinants of postoperative QOL through the metric of whether the primary site of health care was rural or urban. What we have learned provides a lens through which to examine the feasibility and efficacy of performing cardiac surgery in a resource-limited setting.

\section{TEAM HEART}

The Rwandan Genocide of 1994 endured approximately 1 million people killed in 100 days of unspeakable violence of one tribe against another. This tragedy also played out in possibly an even more devastating manner in that it destroyed much of the country's health care capacity. When rebuilding of the health care system began in the early 2000s, a high incidence of heart failure was identified in hospitalized patients. This was discovered to be due primarily to RHD. Team Heart was formed in 2006 in response to a request from the Minister of Health to address the burden of RHD with corrective heart surgery. Since then, the goal of Team Heart has been to provide high-quality humanitarian cardiac care to Rwandans with the vision of not only addressing RHD with surgery but also engaging in disease screening and prevention and patient education, all while focusing on information and skill transfer with the ultimate goal of establishing sustainable cardiac care in Rwanda. Team Heart has worked closely with the Rwandan Ministry of Health and the Rwanda Heart Foundation to organize annual surgical trips to provide country-wide postoperative and anticoagulation monitoring and nursing care, as well as develop plans for a cardiac care center to be built in the capital city of Kigali. Team Heart is structured as a 501-C3 nonprofit organization in the United States and is a registered independent nongovernmental organization in Rwanda (Table 1).

\section{LOGISTICS}

Each year, the team is composed of 45 to 50 medical volunteers, including surgeons, cardiologists, intensivists, anesthetists, intensive care unit, and step-down nurses, pharmacist(s), perfusionists, biomedical engineer(s), trainees in general and thoracic surgery, cardiac anesthesia, cardiology, and nonmedical volunteers, including corporate volunteers who perform myriad duties both in and out of the hospital. In the first few years, participants were predominantly recruited from Brigham and Women's and
Massachusetts General Hospitals. Currently, the most recent edition of the team has members from 5 different countries, 11 different states, and 17 hospitals. There are 10 members who have traveled with the team each year from the inception of the project (Table 2).

\section{FUNDING}

Team Heart has received grants-in-aid from Edwards, St Jude, Inc, and Medtronic, Inc. Furthermore, for each of the last 3 years, Team Heart has been awarded the Every Heartbeat Matters Award from Edwards Lifesciences Foundation and the Thoracic Research Foundation for the support of various aspects of this work. This effort is also supported by an ongoing philanthropic effort that is organized and managed by the Executive Director of Team Heart. All team members take vacation time and pay for their own travel. The Ministry of Health of Rwanda underwrites lodging for a portion of the team volunteers for the duration of the trip.

\section{EQUIPMENT AND SUPPLIES}

Much of the essential equipment has been generously donated to Team Heart. For example, heart-lung machines and intravenous infusion pumps at end-of-service in the United States, but serviceable, have been donated from US-based hospitals affiliated with members of the surgical team, reconditioned, and shipped to Rwanda by Team Heart. Serviceable hemodynamic monitors were donated to the team in 2006. These are currently in use in the operating room and the intensive care unit in King Faisal Hospital, the hospital that hosts the visiting team.

Heart valves and annuloplasty rings have been donated as gifts-in-kind by St Jude Medical, Inc, Edwards Lifesciences, LivaNova, and OnX, Inc. Cardiac surgical instruments have been donated by Scanlan International, Inc. Perfusion supplies have been donated by Medtronic, Inc. Each year, approximately 1500 pounds of supplies consisting of perfusion packs, suture material, thoracic drainage catheters, dressings, intravenous tubing, intravenous fluids, and anesthesia supplies are purchased or donated as in-kind gifts, gathered in a storage facility outside Boston, meticulously labeled and packed to meet Rwandan Customs requirements, and air-freighted to Kigali. All supplies must have expiration dates at least 6 months after their projected arrival in Rwanda to ensure that outdated supplies will not be used during the visit. All necessary medications accompany the team. These are purchased from or, as in 2017, donated by the hospital pharmacy of the lead surgeon.

\section{PATIENT SELECTION}

A group consisting of 2 cardiologists and 2 cardiac sonographers arrives in the country approximately 10 days before the surgical team and the start of surgery. This group, assisted by local and US nurses, residents, and students, visits sites around the country and screens 75 to 100 
TABLE 1. Team heart mission

Mission statement
Working in partnership with the Rwandan Ministry of Health, the
Rwanda Heart Foundation, and select global partners, Team Heart will
address the burden of cardiac disease with the following goals:
- Establish a sustainable regional center of excellence in cardiac
care, including cardiac surgery, a heart catheterization lab,
rehabilitation and prevention, research and education in
partnership with Rwanda local partners.
- Address the situation of adolescents and young adults who have
advanced RHD in Rwanda with surgical intervention to return to
productive and fulfilling life.
- Prevent advanced RHD through a combined effort of surveillance,
prevention, education and early intervention. This will prove to be
an example of an effective, countrywide intervention against RHD
that can inspire a scalable model in the region.
- Support advocacy and poverty reduction initiatives for the
population of marginalized individuals who have chronic heart
disease and the resulting impact on their ability to support
themselves and their family.

RHD, Rheumatic heart disease.

potential candidates for surgery who have been referred by a local cardiologist. The majority of these candidates are among the most socioeconomically disadvantaged - and therefore, the most vulnerable - of Rwanda, who often have advanced disease because of the lack of access to appropriate care. The data from this screening are carefully compiled, and on the day before the beginning of surgery, the entire visiting and local team meets for the purpose of establishing an operative list. A total of 16 cases are completed over the course of 8 days ( 2 cases per day). Given the disproportionate number of potential surgical candidates to the number of cases that can be performed, the selection process is both challenging and anguishing. The team is often left with the knowledge that some of the patients not selected will likely not survive until Team Heart or another expatriate team returns. Given the serious nature of these decisions, the process is inclusive, and all opinions are considered.

\section{SURGICAL OUTCOMES}

Over the space of 10 trips, 149 procedures were performed, representing 200 valve replacements, 12 mitral valve repairs, and 20 tricuspid valve repairs. Of those patients who underwent valve replacement, 175 received mechanical valves and 25 received bioprosthetic valves. Men represented $45.7 \%$ of the patient population, and the average patient age was 25.09 years (range, 11-45 years). Early mortality, classified as mortality within 30 days of surgery, was $4.7 \%$ (Table 3). Overall mortality from all causes was $9.4 \%$.

\section{QUALITY OF LIFE EVALUATION}

In addition to providing cardiac surgery for adolescents and young adults with critical valvular disease, we aimed
TABLE 2. Team heart composition

\begin{tabular}{l}
2017 \\
- 20 physicians (of which in-training: 2 surgical fellows, 2 surgical \\
residents, 3 cardiology fellows, 2 anesthesia residents) \\
- 23 nurses (9 ICU, step-down, 3 OR, 1 screening) \\
- 2 OR Techs \\
- 4 sonographers \\
- 3 perfusionists \\
- 2 pharmacists \\
- 1 biomedical technician \\
- 11 nonmedical volunteers \\
\hline 2017 -Team Heart members hailed from 11 different states and 5 \\
countries (United States, Germany, Brazil, Canada, and Australia) \\
17 different hospitals \\
$2016-12$ states and 5 countries (United States, Germany, Brazil, Canada, \\
and Australia) \\
20 different hospitals \\
2015 - 12 states and 3 countries (United States, Germany, and Uganda) \\
17 different hospitals \\
$2014-12$ states and 2 countries (United States and Germany) \\
17 different hospitals \\
\hline
\end{tabular}

$I C U$, Intensive care unit; $O R$, operating room.

to quantify the QOL of patients who have undergone open heart surgery in Rwanda. The Ferrans and Powers Quality of Life Index Cardiac Version was administered to 114 patients (63 female, 46 male, 5 unspecified) who had undergone cardiac surgery through Team Heart for treatment of RHD. The surveys divided the domains into 4 subcategories (Health and Functioning, Social and Economic, Psychological/Spiritual, and Family) along with calculating a total QOL score for each patient. A Rwandan nurse affiliated with Team Heart administered each survey on an individual basis (both in English and Kinyarwanda) to provide any necessary assistance with translation or literacy. All surgeries were performed between 2006 and 2014, so patients surveyed represented a variety of postoperative time periods. These patients came from villages, towns, and cities all over Rwanda, representing at least 25 of the 30 districts.

Overall QOL scores showed no statistically significant difference between men and women, or between patients seeking care at urban versus rural health centers. However, Social and Economic QOL scores showed statistically significant differences between each of these groups. For the entire patient population, the mean total Quality of Life Index score was $20.79 \pm 4.07$ on a scale from 0 to 30 , where 30 represents the highest possible QOL. Women had significantly lower "Social and Economic" sub-scores $(16.81 \pm 4.17)$ than men $(18.64 \pm 4.10)(P<.05)$ (Figure 1). Patients who reported receiving their followup care in rural health centers also had significantly lower "Social and Economic" sub-scores $(15.67 \pm 3.81)$ when 
TABLE 3. Ten-year clinical experience of cardiac surgery in Rwanda

\begin{tabular}{|c|c|c|c|c|c|c|c|c|}
\hline Year & No. of cases & No. of male & Mean age, $y$ & No. of implanted valves & $\begin{array}{l}\text { Mechanical } \\
\text { valves }\end{array}$ & $\begin{array}{c}\text { Bioprosthetic } \\
\text { valves }\end{array}$ & $\begin{array}{l}\text { Discharged on } \\
\text { Coumadin }\end{array}$ & $\begin{array}{c}\text { Early } \\
\text { mortality }(<\mathbf{3 0} \text { d })\end{array}$ \\
\hline 2008 & 11 & 10 & 28.1 & 8 & 7 & 1 & 8 & 0 \\
\hline 2009 & 13 & 3 & 25.5 & 10 & 3 & 7 & 3 & 1 \\
\hline 2010 & 14 & 7 & 23.5 & 18 & 13 & 5 & 8 & 3 \\
\hline 2011 & 15 & 9 & 27.2 & 22 & 16 & 6 & 10 & 0 \\
\hline 2012 & 16 & 6 & 25.1 & 25 & 19 & 6 & 15 & 0 \\
\hline 2013 & 16 & 7 & 26.6 & 20 & 20 & 0 & 15 & 0 \\
\hline 2014 & 16 & 5 & 24.1 & 24 & 24 & 0 & 14 & 0 \\
\hline 2015 & 16 & 7 & 22.3 & 25 & 25 & 0 & 15 & 2 \\
\hline 2016 & 16 & 3 & 22.1 & 25 & 19 & 0 & 14 & 1 \\
\hline 2017 & 16 & 5 & 26.4 & 23 & 29 & 0 & 16 & 1 \\
\hline 10 trips & 149 & 62 & 25 & 200 & 175 & 25 & 102 & 7 \\
\hline
\end{tabular}

Other procedures: atrial septal defect secundum repair with pericardial patch, pacemaker placement, lead placement, left atrial appendage ligation, patent foramen ovale closure, pericardiocentesis, and pericardial window.

compared with patients receiving their follow-up care in urban health facilities $(18.28 \pm 4.16)(P<.005)$ (Figure 2).

Responses to more global questions revealed that the patients had an encouraging level of community, professional, and family engagement. Some $61.4 \%$ of patients said that they were moderately satisfied to very satisfied with "their ability to take care of their financial needs," and $80.7 \%$ said they were moderately satisfied to very satisfied with "their ability to take care of family duties." Given that these patients preoperatively were in advanced stages of RHD and would likely be dead or in the last throes of their disease without surgery, this represents a striking and hopeful positive level of self-reporting.

\section{STEPS TOWARD A COMPREHENSIVE CARDIAC SURGERY PROGRAM IN RWANDA}

The goal of Team Heart is to facilitate a partnership with the Rwanda Ministry of Health to establish a sustainable, independent, dedicated cardiac care center for children and

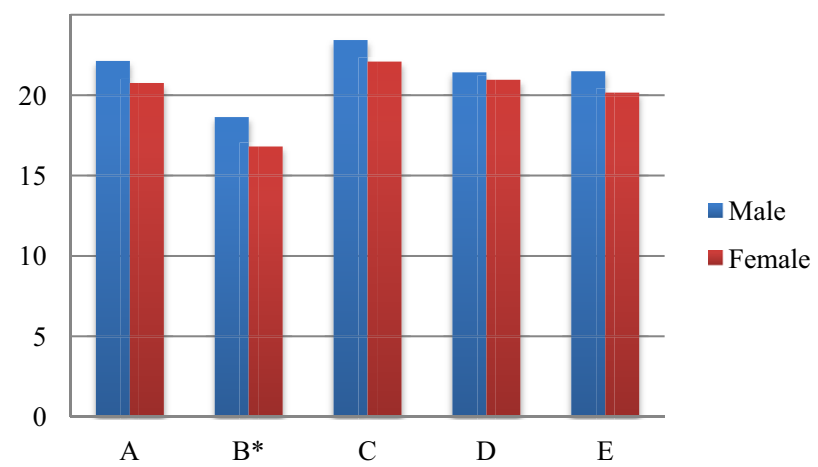

FIGURE 1. Differences in QOL between male and female patients. A, Health and functioning. B, Social and economic. C, Psychologic/spiritual. D, Family. E, Total QOL score. ${ }^{*} P<.05$. adults with all forms of heart disease, which would be a center of excellence in the country and for all of East Africa (Video 1). Of necessity, the Center would initially be staffed largely by expatriate physicians and nurses, while their Rwandan counterparts are being trained. Over time, it is anticipated that the staff will transition to primarily Rwandan nationals. Clearly, one such center is not adequate for the entirety of the Rwanda population. However, when operating at full capacity, it will become the major focus of clinical care, education, and research for cardiovascular disease for Rwanda and the region. This success will foster replication in the region over time. The partnership will strengthen patient care options available in Kigali, Rwanda, on 3 levels by expanding local capacity for cardiac surgery, reinforcing registry-based secondary prophylaxis, and enhancing treatment of streptococcal infections. Currently, Team Heart functions within the existing health care infrastructure of Rwanda, but with its own financing, management, and staff organizations. The scaling up that this vision entails cannot occur on the basis of humanitarian and philanthropic efforts alone. To address this issue,

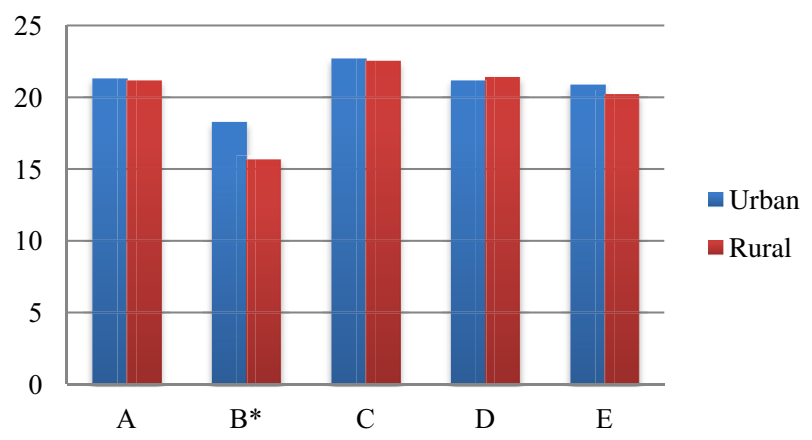

FIGURE 2. Differences in QOL between patients seeking care at urban and rural health centers. A, Health and Functioning. B, Social and economic. C, Psychologic/spiritual. D, Family. E, Total QOL score. $* P<.005$. 


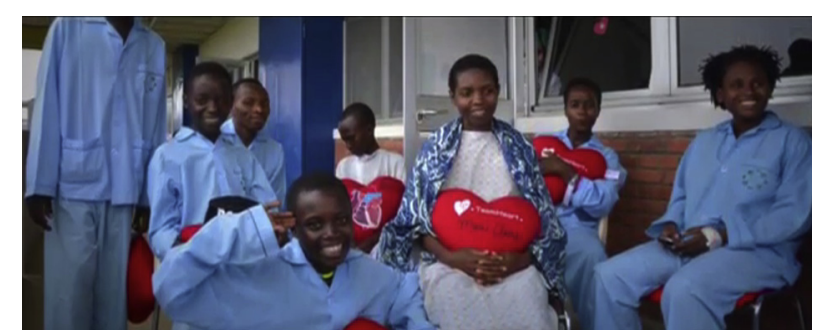

VIDEO 1. Team Heart is a nonprofit organization that aims to address and prevent RHD in Rwanda. Team Heart's history and mission are explained, with visual story telling of their journey. Video available at: http://www. jtcvsonline.org/article/S0022-5223(18)30065-5/fulltext.

parallel efforts are ongoing to engage the Rwandan government in a plan to incorporate funding for cardiovascular care in the national healthcare planning paradigm. The goal is for cardiovascular care to become a self-sustaining module of the Rwandan health care system, interdependent on the primary care and prevention modules already in place and arising throughout the country.

\section{TRAINING OF CRITICAL PROVIDERS}

An important piece of this transition is the shift in responsibility of the medical/surgical staff, which will occur through continued education of the local health care workforce. The most time-consuming hurdle on the path toward sustainability is the identification and training of a local cardiac surgeon. Accordingly, efforts were made early in Team Heart's presence in Rwanda to identify such an individual and to explore the routes available for him/her to be trained properly. Such an individual has been identified, and Team Heart is now working closely with the Rwandan Ministry of Health in supporting the mentorship of this resident as he pursues his training in general and cardiothoracic surgery at the University of Witwatersrand in South Africa. While he completes his training, other key personnel are being identified and trained.

\section{IN-COUNTRY EDUCATION AND SKILL TRANSFER}

In addition to facilitating distant training, in-country surgical education and skill transfer have been important components of the Team Heart model. During initial visits, the staff cardiothoracic surgeon was the first assistant for portions of procedures and observed many others. Multiple medical students and residents from the medical school at the National University of Rwanda and from King Faisal Hospital observed each case. Conscious mentoring by Team Heart surgeons served to increase interest in the field of cardiac surgery and awareness of the need for the intervention within Rwanda. Also, cardiac anesthesiologists from Team Heart have worked closely with local Rwandan anesthesiologists and anesthesia trainees during its surgical trips to provide education in intraoperative and postoperative anesthetic care. The team has also used intraoperative transesophageal and pre- and postoperative transthoracic echocardiography as teaching tools for discussing patient selection, operative procedures, and postoperative care. Nursing education has occurred at both the bedside and through the sharing of resources. Seminars have been facilitated with King Faisal Hospital nursing leadership to provide education on diagnosis and care, from preoperative through postoperative, in a variety of settings. Team Heart further continues to be committed to working with supporting nursing education at both the Baccalaureate and Masters levels in partnership with the Kigali Health Institute and the Biomedical Research Center. In 2009, an individual was identified with interest in cardiac perfusion. A training program in India was located, and that candidate completed the training curriculum. Afterward, this candidate has worked closely with Team Heart during its subsequent trips to assist in providing cardiac perfusion during cases. As education of the local team continues, Team Heart will remain involved in the role of mentorship. Over time, the group plans to gradually increase the responsibility of the Rwandan team, expecting them to demonstrate their competency with increasingly complicated procedures.

\section{ROBUST SCREENING AND PREVENTION PROGRAMS}

Another step toward managing the burden of RHD in Rwanda is delineating its true burden and the extent of the disease. In 2011, Team Heart carried out the first echocardiographic prevalence survey in the Gasabo district of the country (which includes Kigali) to help raise awareness of the problem of RHD and to identify the age groups most affected. In addition to attempting to determine the prevalence of RHD in a sample of Rwandan school children using the 2012 World Heart Federation echocardiographic criteria, the purpose of this study was to identify those individuals who have not yet progressed to acute RHD but could benefit from earlier intervention. ${ }^{11,12}$ The findings of this study demonstrated an RHD prevalence of $6.8 / 1000$ children examined (95\% confidence interval, 4.2/100010.9/1000). This indicates a significant burden of RHD in Rwanda and supports a need for defined public health programs to control strep throat and acute rheumatic fever in children. Secondarily, it revealed the need to work with partners to identify and overcome barriers to primary care that typically hinder children and young adults from seeking treatment for the sore throats and skin infections that may precipitate rheumatic fever. Such research not only helps define the size of local problems but also aids in the evolution of effective approaches to develop and implement these initiatives: a comprehensive school health program and the requisite public policy for improving it; an educational curriculum for healthcare workers and the public; an echocardiographic screening 
program; a registry of identified RHD cases; a program to identify the strains and serotypes of group A streptococci involved in rheumatic fever and RHD in Rwanda; a program for early treatment of group A streptococcal infections among school-aged children; and a promotion of secondary prophylaxis of RHD. ${ }^{13-16}$

\section{CHALLENGES TO PROVIDING CARDIOVASCULAR CARE IN A RESOURCE-LIMITED SETTING}

Rwanda is classified as a "third-world" entity; however, the country has made and continues to make tremendous strides towards economic recovery and growth that have surpassed the development of many other countries with this designation. That said, specific surgical issues within the Team Heart experience were many, presenting real challenges to providing complex cardiovascular care for patients within this resource-limited setting.

First and foremost, the restricted duration of each Team Heart visit and the available human resources could only accommodate a minimum expatriate team to partner with Rwandan personnel. Each ensuing year has presented the charge to make the volunteer team smaller and smaller to promote sustainability while optimizing the learning opportunity and participation among the local care providers. There is the general need to have enough expatriate providers to carry out the daunting task of the operative component of the trip and shepherd the postoperative care. However, there remains a balancing act of attempting not to be overbearing and to allow for inclusiveness among the native providers as well, such that skill transfer and teaching are prioritized.

Once a cohesive team is assembled, patient selection becomes the next critical challenge. This is the most difficult and daunting aspect of the trip each year. Many patients with severe disease are discovered through the Team Heart screening program, but constraints of time and resource availability only allow for care to be extended to those with the best chances of survival and overall improvement. Given these constraints, only 16 patients can be offered surgery each trip. Unfortunately, this leaves behind many critically ill, young patients who, in many cases, will not live to see the next year for the return trip.

Once patients are selected, size limitation is the next challenge. Many of the patients seen are quite small because of their chronic cardiac dysfunction and as a sequelae of failure to thrive. However, the team uses a lower weight limit of $30 \mathrm{~kg}$, which in many ways stretches the margins of our perfusion equipment. In general, patients tend to have small aortas, apart from those with aortic valve disease. This anatomic feature poses some challenges with respect to safe cannulation. Atria are large, so valve exposure is generally good. The chest sizes are small relative to the enlarged heart size. Overall, extreme technical agility is critical for cannulation and transitioning these patients on and off cardiopulmonary bypass without causing untoward harm.

Availability of blood was a serious problem in the first 6 to 7 years. Blood was kept off site and was at least 1 hour away. Take-backs were to be avoided at all costs. In the last 3 to 4 years, there has been the ability to request platelets, fresh-frozen plasma, and cryoprecipitate. Also, there is always 4 units of packed red blood cells available for each patient. We do not offer reoperative heart procedures now because of the enormous backlog of unoperated patients and the fact that we have a limited number of operative openings on any given trip.

Care in the intensive care unit, in general, is superb, because Team Heart has provided dedicated intensive care unit physicians and nurses who are intimately involved in the care of the patients alongside native providers. There is round-the-clock immediate availability of transesophageal echocardiography, cardiac anesthesia, surgery, pharmacy, and any other resources that are required. The team often comments that the resources available for care in the intensive care unit were better than those in the United States.

As to causes of death, the majority are noted to be anticoagulation-related deaths and the unfortunate propensity to use intravenous vitamin $\mathrm{K}$ to reverse elevated international normalized ratios even in patients with mechanical valves, with subsequent valve thrombosis. Also, in terms of postoperative care problems, a principal one was difficulty with patients gaining access to care facilities for care after discharge because of the distance from the center and lack of resources, financial and otherwise. This eventuated in delayed diagnosis and treatment of heart failure in a significant number of patients. Precipitous heart failure and demise has been the outcome in a select number of cases over the 10-year experience.

\section{CONCLUSIONS}

This review assessed the outcomes of surgical treatment of RHD in Rwandan adolescents and young adults and found that the surgery is associated with good clinical outcomes. There is much improvement of heart function and gratifying clinical recovery of patients, with measurable improvement in QOL. This report represents the first account of a long-term humanitarian effort to develop sustainability in cardiothoracic surgery in Rwanda with acceptable outcomes. We have demonstrated the effectiveness of using volunteer teams to deliver care, transfer knowledge, mentor local personnel, and train key individuals to assist in mitigating the burden of cardiovascular disease in sub-Saharan Africa. ${ }^{15}$ Moving forward, preventive measures of acute rheumatic fever and RHD should be among health prevention program priorities. Team Heart has laid the foundation for a comprehensive program that could eventually eliminate RHD from the country. 
Finally, through a decade of dedicated effort and demonstrated success, a platform has been created that can be leveraged for the creation of the desperately needed next level of care for this neglected part of the world, namely, a dedicated cardiac care center for Rwanda and the region.

\section{Webcast}

You can watch a Webcast of this AATS meeting presentation by going to: https://aats.blob.core.windows.net/ media/17AM/2017-05-01/BallroomABC/05-01-17_Ball roomABC_1040_Bolman.mp4.

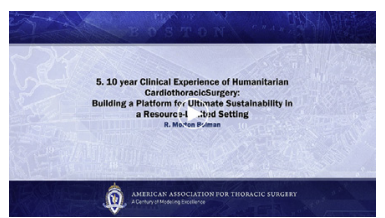

\section{Conflict of Interest Statement}

Authors have nothing to disclose with regard to commercial support.

The Team Heart experience would not be possible without the gracious in-kind donations of several organizations and the many volunteers over the years. The sustainability of this project has been heralded not only by the efforts of the organization but also the gracious support of the Rwandan government, its leadership as well as the patient advocates, many of which have been patients themselves that now live healthy lives as a result of the cardiac care they have received.

\section{References}

1. Mocumbi AO, Ferreira MB. Neglected cardiovascular diseases in Africa: challenges and opportunities. J Am Coll Cardiol. 2010;55:680-7.

2. Wyber R, Zühlke L, Carapetis J. The case for global investment in rheumatic heart-disease control. Bull World Health Organ. 2014;92:768-70.

3. Gaziano TA, Bitton A, Anand S, Abrahams-Gessel S, Murphy A. Growing epidemic of coronary heart disease in low- and middle-income countries. Curr Probl Cardiol. 2010;35:72-115.

4. Zühlke L, Mirabel M, Marijon E. Congenital heart disease and rheumatic heart disease in Africa recent advances and current priorities. Heart. 2013;99:1-8.

5. Zühlke L, Engel ME, Karthikeyan G, Rangarajan S, Mackie P, Cupido B, et al Characteristics, complications, and gaps in evidence-based interventions in rheumatic heart disease: the global rheumatic heart disease registry (the REMEDY study). Eur Heart J. 2015;36:1115-1122a.

6. Grimes CE, Henry JA, Maraka J, Mkandawire NC, Cotton M. Cost-effectiveness of surgery in low- and middle-income countries: a systematic review. World $J$ Surg. 2014;38:252-63.

7. Chao TE, Sharma K, Mandigo M, Hagander L, Resch SC, Weiser TG, et al. Costeffectiveness of surgery and its policy implications for global health: a systematic review and analysis. Lancet Glob Health. 2014;2:e334-45.

8. Yankah C, Fynn-Thompson F, Antunes M, Edwin F, Yuko-Jowi C, Mendis S, et al. Cardiac surgery capacity in sub-Saharan Africa: quo vadis? Thorac Cardiovasc Surg. 2014;62:393-401.

9. Swain JD, Mucumbisti J, Rusingiza E, Bolman RM, Binagwaho A. Cardiac surgery for advanced rheumatic heart disease in Rwanda. Lancet Glob Health. 2014; 2:e141-2.

10. Binagwaho A, Farmer PE, Nsanzimana S, Karema C, Gasana M, de Dieu Ngirabega J, et al. Rwanda 20 years on: investing in life. Lancet. 2014;384:371-5.

11. Swain JD, Pugliese DN, Mucumbitsi J, Rusingiza EK, Ruhamya N, Kagame A, et al. Partnership for sustainability in cardiac surgery to address critical rheumatic heart disease in sub-Saharan Africa: the experience from Rwanda. World J Surg 2014;38:2205-11.

12. Marseille E, Morshed S. Essential surgery is cost effective in resource-poor countries. Lancet Glob Health. 2014;2:e302-3.

13. Mucumbitsi J, Bulwer B, Mutesa L, Ndahindwa V, Semakula M, Rusingiza E, et al. Prevalence of rheumatic valvular heart disease in Rwandan school children: echocardiographic evaluation using the World Heart Federation criteria. Cardiovasc J Africa. 2017;28:285-92.

14. Alkire BC, Vincent JR, Burns CT, Metzler IS, Farmer PE, Meara JG. Obstructed labor and caesarean delivery: the cost and benefit of surgical intervention. PLoS One. 2012; 7:e34595.

15. Medlin CA, Chowdhury M, Jamison DT, Measham A. Improving the health of population: lessons of experience. In: Jamison DT, Breman JG, Measham AR, Alleyne G, Claeson M, Evans DB, et al, eds. Disease Control Priorities in Developing Countries. 2nd ed. New York: Oxford University Press; 2006:1245-60.

16. Notrica MR, Evans FM, Knowlton LM, Kelly McQueen KA. Rwandan surgical and anesthesia infrastructure: a survey of district hospitals. World J Surg. 2011; $35: 1770-80$.

Key Words: humanitarian cardiac surgery, rheumatic heart disease, sub-Saharan Africa, Team Heart, Rwanda

\section{Discussion}

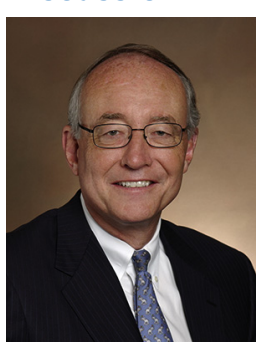

Dr David A. Fullerton (Aurora, Colo). One of the things we must realize is that within the next 10 years the leading cause of death worldwide will be cardiovascular disease. The effect that cardiovascular disease is having on the population of any given country and their families, particularly in lower and lower middle income countries, is truly devastating, and that is in part why I think your work is so poignant.

As you pointed out, it has only been 2 and a half decades since Rwanda was absolutely devastated by violence, and not only was its population destroyed but its economy. Over the last 10 years, it is interesting to see that there are only a small number of countries, in fact 3 , that would be defined by the World Health Organization as residing in lower income strata that have been able to rise out of that into a middle income strata, and Rwanda leads the way in that regard. That effect on the economy of the population is directly associated with the impact and the improvements of the health of its population, and this is where you and your team have played an incredibly vital role. Could you please extrapolate as to how this type of work might be expanded worldwide? It requires tremendous infrastructure, it requires a large amount of resources and money, not to mention the human expenditures that you and your team put forth every year. So if you could idealize what you might do, Chip, how would you put that together?

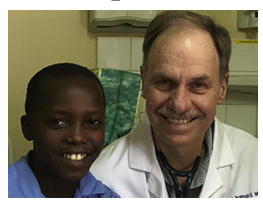

Dr R. Morton Bolman (Burlington, $V t$ ). This concept of sustainability and expansion to other areas of need is one we struggle with all the time, and it is why we have tried to focus on taking young trainees with us every 
year. These trainees consist of medical students, general surgery residents, cardiac surgery fellows, anesthesia residents, cardiology fellows, and others. In addition to performing vital roles in the surgical mission, it is important to expose these young trainees to this type of work early in their careers, so that they will make an effort to contribute in some manner later in their careers. I just ran into one of our former trainees today who is here today. She is now on the faculty at the Brigham and is starting her own humanitarian project in Lima, Peru, in thoracic surgery. So you try and pay it forward.

Another major focus is that of knowledge and skills transfer. We encourage all our team members to try to perform as much education of their Rwandan counterparts as possible. This has led to a noticeable improvement over the years in the skill levels of the nurses, anesthetists, perfusionists, operating room scrub technicians, and so forth. Having the opportunity to present this work at a society with the profile of the American Association for Thoracic Surgery is of inestimable benefit. On behalf of everyone who is involved in humanitarian efforts in cardiac surgery, I express my gratitude. I think the major thoracic organizations can advance these important efforts by establishing viable pathways for young surgeons for presentation and publication of high-quality, peer-reviewed studies, be they clinical or research in nature.

To address your question specifically, there are currently so few resources being dedicated to this type of effort. It is important that we try to pool what resources there are and leverage them to maximize the benefit that can be delivered to those without access to care. Training, particularly of specialists, but also of nurses and support staff is of critical importance. That has been our focus with the training of a young surgeon in South Africa. He is here at this meeting. We feel a certain amount of pressure to establish a dedicated cardiac center in Rwanda. If he comes back trained and ready to begin his career as a cardiac surgeon, we have to have a hospital for him to work in. There isn't one now. There is not a full-time program there. So our challenge in the next 2 to 3 years is to get a hospital built for him to be able to work in and be able to make a living and support his family. It's a multistep process as you well know from your work in Nepal, and we look toward to working with you and other partners in this quest.

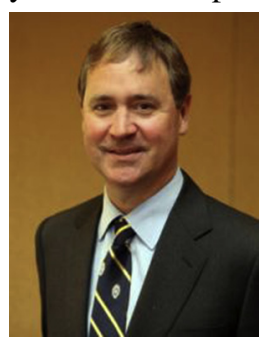

Dr M. Moon (St Louis, Mo). This idea of globalization and changing boundaries has been around over the last decade or 2, and I encourage everyone to review Drs Jonas and Cox's addresses previously from the American Association for Thoracic Surgery that were motivating.

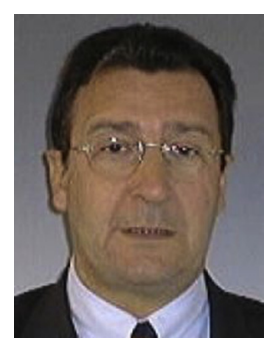

Dr J. Pomar (Barcelona, Spain). We recently heard General McChrystal, a beautiful and important insight into what and how and where our activity is going to evolve, and I think this is important. You already mentioned that we are working on a global system, a global project, and it is our personal and team help to those requiring an education, which I think is the most important thing, and of course healthcare the most important thing to do.

Resources we know very well are scarce, but we need to overcome this with our attitude and with our honest work. As my good friend Peter Zilla has mentioned very often, world solutions are not necessarily the solutions for developing countries and probably are very different. So we need to do, and I think this should be one of the most important things for all of us, a lot of research about what they really need. And as he mentioned, it is not that easy. You need different steps, different solutions, different ways of thinking, and this research I think is going to help a lot.

It was also mentioned that the European Association for Cardiothoracic Surgery and many European surgeons, some of them sitting here, are doing a lot of different projects, and we are proud of this. But I think the only way to do it efficiently is by doing it all together. If every society or every group is doing that alone, I think together doing something really much more efficiently is going to be much better for all. Thank you very much and, again, congratulations.

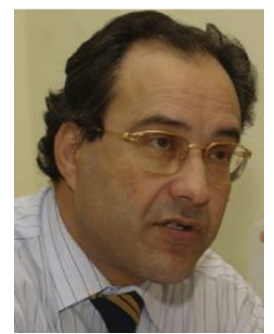

Dr. M. Antunes (Coimbra, Portugal). There are several projects similar to yours around the world. Africa is in particular need for these types of projects, because south of the Sahara there was nothing until a decade or so ago, 2 decades ago.

I participate in a giant project that involves the Chain of Hope of Europe, the British, the French, Swiss, and ourselves in Portugal, and for the last 16 consecutive years we have traveled with my team to Maputo, Mozambique, where we have established a similar program. We have now operated on more than 1500 cases, and after 12 years we succeeded in training 2 local surgeons and 2 perfusionists who now do 2 or 3 cases a week every week, so something like between 100 and 150 cases. They concentrate themselves, believe it or not, or surprisingly, in small children with complex congenital cardiac problems. I just received the news that the local team just did a switch operation on a 14day-old baby, which is really astonishing.

I was surprised to see the number of cases you did, mostly, of course, are rheumatic cases with valve disease. I was 
surprised to see how many replacements you did, the majority of your operations were replacements. I think that in this type of population to replace a valve is really not a great service, and we intensify our efforts to repair valves, even knowing that sometimes you don't have a very long-term good result. But if you take a child from the age of 8 years with a mitral repair that requires replacement by the age of 18 years, we have done a great service. Can you comment on that?

Dr Bolman. I certainly anticipated that question from you. I admire your work with valve repair for rheumatic disease. We share your concerns about using mechanical valves in this setting especially in a country that when we first went there in 2008, there was one place you could get an international normalized ratio in the country, and that was in the capital city. Through the Every Heartbeat Matters Award and others, we have now set up a program around the country where at 37 sites we can get international normalized ratio testing. This means there is a testing site within reasonable distance of all of our patients.

We share the same concerns about the long-term problems associated with mechanical and biologic prostheses. So, the first 2 or 3 years we tried a number of repairs, and we were disappointed. We were performing complex repairs with bovine pericardial leaflet extensions and extensive leaflet repairs and annuloplasties. At the end of the day, with the exception of the tricuspid valve with purely functional, secondary tricuspid regurgitation, where ring annuloplasty has proven satisfactory, we have not been happy with the durability of the repairs.

It is important to add that in this setting reoperation is not an option. With such a backlog of unoperated patients, and such limited resources including blood products, we think the need to pick the one operation that is likely to get the patient out of heart failure and last as long as possible, realizing there will not likely be a second operation available.

Dr Antunes. The problem is that with prostheses, reoperation is not an option because they will die by failure of the prosthesis, even thrombosis or degeneration of the bioprosthesis. I know it is a difficult balance to obtain.

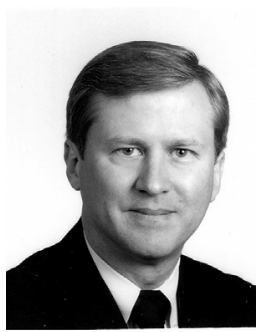

Dr W. Holman (Birmingham, Ala). When I first started at Duke, Chip Bolman was my senior resident, and here I am 40 years later still asking him questions. I have a friend who was at the university with me years ago and then he went back and practiced for many years in Mumbai where they do many mitral commissurotomies closed. Have you talked to any of the surgeons from India where they have maybe not as severe a limitation of resources but they do have to deal with limitations and have developed a methodology for doing closed procedures followed by open procedures, admittedly reoperations but maybe not as difficult.

The other statement is just a social comment coming from a state that has counties without even a physician much less a hospital. If members feel moved by Chip's talk, and they should be, if you do not have the time or the ability to travel abroad, you can always look around and find a great need for cardiac surgery in your own locale.

Dr Bolman. With respect to the commissurotomy, we have not done any closed commissurotomies, but we have done a few open commissurotomies as part of our mitral repairs. When we see mitral stenosis, often it is part of a mixed lesion with mitral insufficiency. The chords are often virtually fused with the valve leaflets, and we have not been confident that any repair of such a valve will be at all durable. Even in most of the cases of pure mitral stenosis that we have seen, the leaflets and chords are just kind of one, and it's hard to imagine a commissurotomy being a durable repair. In this circumstance, we have elected to replace the valve, knowing it is an imperfect solution. We have had to do our best to ensure that postoperative anticoagulation can be managed safely. This has included procuring warfarin, international normalized ratio machines, and testing strips for the entire country, and trying to make sure compliance is adequate by providing transportation and co-pays for clinic visits. There have been patients who have fallen through the cracks, to be sure, but overall the results have proven gratifying. 